\title{
UIVO OTOBIOGRÁFICO
}

Silas Borges Monteiro ${ }^{1}$

\section{Margem}

Este ensaio quer experimentar a criação de uma margem com Derrida e Ginsberg; faz isso com Otobiographies (1979) e três poemas de Ginsberg: Improviso em Pequim (1985), Kaddish (1958) e Uivo (1956). Neste ensaio, toda escritura faz rastro da própria vida; todo texto é autoconfissão de seu autor. (NIETZSCHE, 2009, § 6)

$\mathrm{O}$ livro de Derrida nasceu de uma conferência. O termo otobiographies, que em francês soa como autobiografia, ao mesmo tempo que soa como um neologismo derridiano, fala da escuta da vida, fala do logos e gramma, fala da vida-morte. Uma autobiografia não é a história de uma vida. Escrever é o gesto de um homem morto e no texto o escritor está morto. Assim, o texto não é a vida do autor: é sua morte-vida.

Esse aprendizado que Derrida tem com Nietzsche será usado como estratégia. Uivo: poema de constituição de si, Kaddish: texto de vida-morte da sua mãe louca; Improviso em Pequim: inescapável compulsão pela escrita.

\section{Um certo livro}

O texto Otobiografias foi o resultado de estudo e docência sobre Nietzsche entre 1970 e 1980. Neste tempo, Derrida trabalhava em torno da teoria da biografia e da autobiografia. Uma autobiografia não é a história de uma vida. Escrever é a escritura de um homem morto e no texto o escritor está morto, deixando o texto ausente de autor. Assim, pois, o texto não é a vida do autor, ainda que se refira a ele: é a morte-vida. Inscrevendo seu nome na vida, Nietzsche o deu à morte e se converteu em morte como vida. Desde o ponto de vista de Derrida, um texto está morto, como uma máquina, e dado que existe como o produto de um homem vivo, sempre está em funcionamento, mesmo distante dele.

Uma autobiografia não pode ser plenamente escrita; está exatamente em todas as partes da vida e dos textos, porém em nenhum espaço concreto. É differánce. Otobiografias é típico do trabalho de Derrida: apresenta uma teoria da escritura, porém a mascara sob um argumento temporário.

\section{Um suposto livro}

Na verdade, serão trazidos aqui, para criar esta margem com Otobiographies, três textos e não um livro. Foram organizados aqui como livro-por-vir. Com isso, se quer, ao dizer: não há livro. Talvez pudéssemos dizer com Derrida que haveria uma espécie de "livro por vir", entendido como "reunido pela dispersão" (DERRIDA, 2004, p. 28), este outro certo livro-porvir que colocamos em margem, que venha a funcionar como um tipo de diafragma. Este livropor-vir que nunca existirá é uma seleção de uivos que ressoam o ensinamento de Nietzsche e sua política do nome próprio. Nomes e máscaras de 1956, 1962, 1994.

\footnotetext{
${ }^{1}$ Estudos de Filosofia e Formação - UFMT; Escrileituras da Diferença: em filosofia-educação - UFRGS; Grupo de Estudos e Pesquisas sobre a Formação do Educador - USP. E-mail: silasmonteiro@me.com.
} 


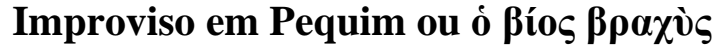

\section{6 minutos ou uma vida}

Assim escreve Ginsberg:

Eu escrevo poesia porque é o melhor caminho para dizer tudo o que penso dentro de 6 minutos ou uma vida inteira.

Quanto cabe de pensamento em seis minutos ou em uma vida inteira? Cabe uma vida inteira em 6 minutos? Podem seis minutos estender uma vida inteira?

Godard, tomado por Hans Lucas: "Mais importante do que durar é viver". Como fala sobre cinema, se opõe à teoria do tartamudo André Bazin, que defendia o realismo e o planosequência, pois queria verdadeira continuidade e profundidade; Godard sempre adotou "o potencial descontínuo da montagem, o corte abrupto e o significado das falsidades de um gesto ou de um olhar. (idem, p. 228) Verdade e continuidade contra interrupções falsas de um olhar.

O meu olhar azul como o céu

É calmo como a água ao sol. (...)

Porque tudo é como é e assim é que é.

E eu aceito, e nem agradeço,

Para não parecer que penso nisso...

Alberto Caieiro (poema XXIII)

Vou a Ezra Pound:

Se for realmente assim, então não seria possível testar a verdade de uma sentença. Falsidade seria tão ilusória como a verdade. Discursos levariam a nenhuma convicção. (POUND, 2005)

Qual o significado das verdades, das falsidades, em seis minutos ou uma vida inteira? Hipócrates, abre seus aforismos dizendo: ó ßíos $\beta \rho \alpha \chi \grave{s} s:$ a vida é breve. Seria óbvio serem seis minutos mais breves do que uma vida? Uma vida menor que seis minutos?

\section{Kaddish ou Escritura-vida}

\section{Salvo o nome da mãe}

Todas as mães são loucas. Em Otobiografias, Derrida afirma: "Não há mulher (...) Salvo a mãe, é claro". (p. 88) A mulher seria a crítica profunda sobre a metafísica ocidental. Em Esporas (2013, p. 60) Derrida vê a mulher como devir, devir-mulher que se faz progresso de ideia. A mulher, assim como a filosofia, veio a tomar distância de uma tradição enclausuradora. Não há mulher. Salvo as mães. "A mãe é a figura sem figura de um figurante" (DERRIDA, 2009 , p. 88); ideia sem pensamento de um idealizador; forma sem contorno de um formador; cena sem palco de um ator.

Otobiografias fala da mulher na sessão intitulada ỏ $\mu \varphi \alpha \check{\lambda}$ ós, termo grego significa "umbigo" ou "chefe", ambiguidade da vida-e-morte, rastro da vida-morte. 
E Naomi? Mãe cantada em judaico profanamente: Kaddish. Não ao Deus santo, mas ao nome da mãe, A. G. brada a quem lhe deu ỏ $\mu \varphi \breve{\alpha} \lambda o ́ s:$

Para a educação casamento colapso nervoso, operação, escola normal e aprendendo a ser louca, num sonho - que vida é essa?

Não se nasce louca: se aprende, assim como a ser normalista. Com o nome da mãe salvo, entoado profanamente, Ginsberg põe abaixo o ideal de mulher. Ora, abaixo todo ideal:

Eu, de qualquer forma, talvez tão velho como o universo - e penso que ele morre conosco - o suficiente para cancelar o que vem depois - Aquilo que veio parte sempre cada vez -

O universo vive a idade de uma vida, em seis minutos.

\section{Uivo ou Verdades ficcionais}

\section{Último poeta público}

"De fato, há algo do profeta do Velho Testamento nele. (...) Uivo fez Allen Ginsberg". (RASKIN, 2004, p. 18) A escritura-lida transcriou Irwin em Allen-Howl-Ginsberg. Howl como escrileitura — termo de Sandra Corazza — "palavra-valise que diz da intersecção barthesiana 'leitor-escritor-texto' e da experiência sensual que conduz o leitor do prazer de ler ao desejo de escrever". (OLINI, 2015, p. 22) Ele aprende a bradar pelas ruas, balançando a cabeça, dizendo frases sem tomar fôlego, asfixiante, apaixonante, vindo-a-ser-texto-carne-voz. Uivo foi lido em público, não para a academia, pois "foram expulsos das universidades por serem loucos \& publicarem odes obscenas nas janelas do crânio". Eles vivem para decidir o que entra e sai do corpo, feito em onda ou átomo, pois são aqueles

que comeram fogo em hotéis mal pintados ou beberam terebentina em Paradise Alley, morreram ou flagelaram seus torsos noite após noite com som, sonhos, com drogas, com pesadelos na vigília, álcool e caralhos em intermináveis orgias,

por aqueles que já não sabiam mais onde começava e terminava um corpo, um texto, uma vida.

\section{Referências}

DERRIDA, Jacques. Esporas: os estilos de Nietzsche (Trad. Rafael Haddock-Lobo e Carla Rodrigues) Rio de Janeiro: NAU, 2013.

Otobiografías. La enseñanza de Nietzsche y la política del nombre propio. Buenos Aires: Amorrortu, 2009.

Papel-máquina. (Trad. Evando Nascimento) São Paulo: Estação Liberdade, 2004.

GINSBERG, Allen. Uivo, Kaddish e outros poemas (1953-1960). (Trad. Cláudio Willer). Porto Alegre: L\&PM Editores, 1984. 
LARSON, Kay. Where the heart beats: John Cage, Zen Buddhism, and the inner life of artists. London: Penguin Books Ltd, 2012, e-book.

MANEVY, Alfredo. Nouvelle Vague. In: MASCARELLO, Fernando (Org.). História do cinema mundial. Campinas: Papirus, 2006. p. 221-252.

MORGAN, Bill; STANFORD, David (ed.). Jack Kerouac and Allen Ginsberg: The Letters. London: Viking Penguin, 2010.

NIETZSCHE, Friedrich. Além do bem e do mal. (Trad. Paulo César Lima de Souza) São Paulo: Cia. das Letras, 2009. e-book

POUND, Ezra. The chinese character as a medium for poetry. In: NADEL, Ira B. (ed.) Early Writings, Poems and Prose. London: Penguin Books, 2005. e-book.

PESSOA, Fernando. Obra poética de Alberto Caieiro. Poema XXIII. Domínio Público. e-book.

RASKIN, Jonah. American scream: Allen Ginsberg's Howl and the making of the Beat Generation. Berkeley, Los Angeles: University of California Press, 2004.

OLINI, Polyana. Noologia do currículo: dramatizações do Projeto Escrileituras. Projeto de Tese. Porto Alegre: UFRGS, 2015. 